\title{
Relationship Between Pack-year History of Smoking and Response to Tumor Necrosis Factor Antagonists in Patients with Rheumatoid Arthritis
}

\author{
DEREK L. MATTEY, ANN BROWNFIELD, and PETER T. DAWES
}

\begin{abstract}
Objective. To determine whether there is a quantitative relationship between smoking history and response to therapy with tumor necrosis factor (TNF) antagonists.

Methods. A history of cigarette smoking was obtained from a questionnaire completed by each patient starting therapy with TNF antagonists since $2002(\mathrm{n}=154)$. A core set of demographic and clinical variables was recorded at baseline and at 3 and 12 months. The extent of smoking was quantified in pack-years (py), with 1 py equivalent to 20 cigarettes per day for 1 year. The association between smoking intensity and response was assessed using contingency tables and logistic regression analysis. Response to therapy was defined according to the European League Against Rheumatism improvement criteria.

Results. There was an increasing trend of no response at 3 and 12 months with increasing py history $[\mathrm{p}$ (trend) $=0.008$ and 0.003 , respectively]. The change in Disease Activity Score (DAS) 28 over the first 3 months was inversely associated with the number of py $(r=-0.28, p=0.002)$. The association of py history with response failure was independent of age, sex, disease duration, baseline disease activity score (DAS28), Health Assessment Questionnaire (HAQ) score, IgM rheumatoid factor, and smoking at baseline. The most significant effect was seen in patients treated with infliximab.

Conclusion. RA patients with a history of smoking were more likely to show a poor response to TNF antagonists. Response failure was associated with the intensity of previous smoking, irrespective of smoking status at initiation of anti-TNF therapy. (First Release May 15 2009; J Rheumatol 2009;36:1180-7; doi:10.3899/jrheum.081096)
\end{abstract}

Key Indexing Terms:

RHEUMATOID ARTHRITIS

BIOLOGICAL THERAPY

\section{TUMOR NECROSIS FACTOR INHIBITOR}

SMOKING
Many recent studies have provided evidence that cigarette smoking is a risk factor in susceptibility to rheumatoid arthritis (RA), and may be associated with the development of more severe disease, especially that involving extraarticular features such as nodules and vasculitis ${ }^{1-17}$. The relationship between smoking and erosive disease is less clear, with some studies showing detrimental effects, while others show no effect or even suggest that smoking may be protec-

From the Staffordshire Rheumatology Centre, University Hospital of North Staffordshire; and Institute of Science and Technology in Medicine, Keele University, Keele, Staffordshire, England.

Supported by the Haywood Rheumatism Research and Development Foundation.

D.L. Mattey, PhD, Staffordshire Rheumatology Centre, University Hospital of North Staffordshire and Institute of Science and Technology in Medicine, Keele University; A. Brownfield, MSc; P.T. Dawes, FRCP, Staffordshire Rheumatology Centre, University Hospital of North Staffordshire.

Address reprint requests to Dr. D.L. Mattey, Staffordshire Rheumatology Centre, Haywood Hospital, High Lane, Burslem, Stoke-on-Trent, StaffordshireST6 7AG, UK. E-mail: Derek.Mattey@uhns.nhs.uk Accepted for publication January 28, 2009. tive against joint damage $4,7,8,10,11,15,16$. Such differences may be due to differences in disease duration or pack-year (py) history between studies. Those studies showing detrimental effects were generally carried out on patients with a longer disease duration and longer smoking history $4,7,8,11$.

The influence of smoking on response to treatment in patients with RA has received little attention, although a recent study has suggested that patients with RA who smoke have a greater need for disease modifying antirheumatic drugs (DMARD) ${ }^{18}$. The authors suggested that the potency of antirheumatic agents may be weakened in smokers, such that greater use of DMARD is needed to control disease activity. This study found that py history was important, with nonsmokers and patients with fewer than 20 py having a significantly higher probability of improvement than heavy smokers ( $>20$ py). A recent study of patients with RA from the British Society for Rheumatology (BSR) Biologics Register also suggests that smoking may influence response to tumor necrosis factor (TNF) antagonists since a lower response rate to the TNF antagonist infliximab was found in current smokers ${ }^{19}$. However, that study did not report on the

Personal non-commercial use only. The Journal of Rheumatology Copyright @ 2009 . All rights reserved. 
quantitative effects of smoking on anti-TNF response. In our study, we have investigated whether there is a quantitative relationship between smoking history and response to TNF antagonists in patients with RA.

\section{MATERIALS AND METHODS}

Study population. Patients were attending a secondary care hospital rheumatology clinic at the Staffordshire Rheumatology Centre, United Kingdom, (Table 1) and satisfied the 1987 American College of Rheumatology criteria for $\mathrm{RA}^{20}$. All patients starting therapy with TNF antagonists since 2002 were entered into the study $(n=154)$. The majority of patients were started with infliximab $(n=83)$ or etanercept $(n=55)$, with a smaller number starting with adalimumab $(n=16)$. They all fulfilled the UK National Institute of Clinical Excellence (NICE) criteria for use of antiTNF therapy and were entered onto the British Society for Rheumatology Biologics Register. A core set of demographic and clinical variables was recorded at baseline, 3 months, and 12 months. These included the Disease Activity Score 28-joint count (DAS28), disability index of the Health Assessment Questionnaire (HAQ) ${ }^{21}$, presence of erosions, C-reactive protein (CRP) and erythrocyte sedimentation rate (ESR), visual analog scale (VAS) pain score, IgM rheumatoid factor (IgM-RF), and presence or absence of rheumatoid nodules. IgM-RF levels were measured using nephelometry and reported in International Units (IU). A level > $60 \mathrm{IU} / \mathrm{ml}$ was considered to be positive 22 .

A history of current or past cigarette smoking was obtained from a questionnaire completed by each patient at the start of the study. Patients were classified as smokers if they had smoked at least 1 cigarette a day for 1 year. The age at which they started smoking and the number of cigarettes smoked per day was recorded. In past smokers, the age at which they ceased smoking was also recorded. The extent of previous smoking was quantified in pack-years, with 1 py equivalent to 20 cigarettes per day for 1 year. Response to therapy was defined according to the European League Against Rheumatism (EULAR) improvement criteria, based on their 3 or 12 -month DAS28 and absolute change in DAS28 from baseline ${ }^{23}$. A nonresponder would show an improvement $<0.6$ or have a final DAS28 score $>$ 5.1. Ethical approval was obtained from the North Staffordshire local research ethics committee, and all patients provided written informed consent.

Statistical analysis. Baseline differences in continuous demographic variables between current smokers, past smokers, and nonsmokers were investigated by analysis of variance (ANOVA). Frequency differences in clinical variables were investigated using contingency tables and chi-squared analysis. Comparisons between patients who had ever smoked (past + current) and those who had never smoked were carried out using Student's t tests or Mann-Whitney U-tests where appropriate. Paired t tests or Wilcoxon's signed-rank test were used to compare variables in smokers and nonsmokers at baseline and 3 months, depending on whether data showed a normal or non-normal distribution. The relationship between changes in disease measures and number of py was calculated using Spearman's correlation. The association between smoking intensity and response to therapy was initially assessed using contingency tables in which py were stratified into 4 categories $(0,1-15,16-30,>30)$ to reflect the intensity of smoking prior to therapy with TNF antagonists. Patients who discontinued prior to their 3-month or 12-month assessment were classed as nonresponders, irrespective of their reason for stopping. These patients were included in the analyses on an intention to treat basis. Data were analyzed using the Mantel-Haenszel chi-squared test for trend. Multivariate logistic regression analysis was used to investigate the association of py with nonresponse, when adjusting for other possible confounders: baseline DAS28, HAQ, number of previous DMARD, etc. A forward stepwise analysis was used to determine the strongest predictors of response failure.

All data were analyzed using Number Cruncher Statistical Software package for Windows (NCSS 2000, NCSS Statistical Software, Kaysville, UT, USA), and GraphPad Prism software (version 1.03, GraphPad Software, San Diego, CA, USA).

\section{RESULTS}

Baseline demographic and clinical features in smokers and nonsmokers. Table 1 summarizes baseline demographic and clinical features of the RA cohort according to their smoking status. The general characteristics were typical of patients with well established, severe RA, including a significant proportion with nodular disease.

A history of smoking was found in 103/154 (66.9\%) patients. Of these, 38/154 (24.7\%) were current smokers at the start of anti-TNF therapy. There was no significant difference in age or age of onset between nonsmokers, past smokers, and current smokers, although current smokers had a shorter disease duration than nonsmokers or past smokers ( $\mathrm{p}=0.03$ by ANOVA). Patients with a history of smoking (past + current) were more likely to be male than female [ 81.8 vs $60.9 \%$; odds ratio (OR) $2.8,95 \%$ confidence interval (CI) $1.2-6.4, p=0.01]$. There was no difference in the frequency of erosive disease between patients who had ever smoked and nonsmokers. However, there was an increase in the frequency of patients with IgM-RF and nodules in patients who had smoked, although this did not achieve statistical significance. The number of years smoked were significantly higher in patients with seropositive disease (30.9 vs 18.3 yrs; $p=0.0004)$ and nodular disease $(30.9$

Table 1. Baseline characteristics of patients with RA stratified by smoking status before treatment with tumor necrosis factor (TNF) antagonists.

\begin{tabular}{lccc}
\hline & $\begin{array}{c}\text { Never Smoked, } \\
\mathrm{n}=51\end{array}$ & $\begin{array}{c}\text { Past Smoker, } \\
\mathrm{n}=65\end{array}$ & $\begin{array}{c}\text { Current Smoker, } \\
\mathrm{n}=38\end{array}$ \\
\hline Age, mean (SD) yrs & $54.5(12.3)$ & $57.7(12.9)$ & $56.4(12.60)$ \\
Age of RA onset, man (SD) yrs & $40.7(14.1)$ & $42.6(13.4)$ & $45.8(11.4)$ \\
Disease duration, mean (SD) yrs* & $13.9(8.4)$ & $15.2(8.6)$ & $10.6(8.3)$ \\
Male:female** & $8: 43$ & $26: 39$ & $10: 28$ \\
Rheumatoid factor, \% & 66.0 & 73.5 & 83.3 \\
Nodules, \% & 52.0 & 64.7 & 66.7 \\
Erosions, \% & 92.0 & 91.2 & 97.4 \\
\hline
\end{tabular}

$* \mathrm{p}=0.03$ (analysis of variance), $* * \mathrm{p}=0.015$ (chi-squared test, $2 \mathrm{df}$ ). 
vs 22.3 yrs; $p=0.006)$. Similarly, the number of py was significantly higher in seropositive patients (16.1 vs 8.9 py; $\mathrm{p}=$ 0.02 ) and those with nodules (18.4 vs $8.0 \mathrm{py} ; \mathrm{p}=0.003$ ).

Comparison of clinical variables at baseline and 3 months in patients with or without a history of smoking. For patients completing 3 months' followup ( $\mathrm{n}=147$ ), paired comparison tests showed significant improvements $(\mathrm{p}<0.0001)$ for all clinical variables in patients with or without a history of smoking (Table 2). Seven patients stopped anti-TNF therapy before the 3-month timepoint. We were unable to collect clinical data on these at the time of discontinuation, so they were omitted from the paired comparison analyses.

At baseline there were no significant differences in clinical variables between nonsmokers and those who had ever smoked. However, at 3 months the measures of disease activity, disability, pain, and patient global assessment (PGA) for those who had ever smoked were significantly higher than in nonsmokers: DAS28 ( $\mathrm{p}=0.005)$, HAQ $(\mathrm{p}=$ $0.01)$, pain VAS $(p=0.0001)$, and PGA $(p=0.0004)$. A paired comparison of the baseline clinical data with that at 12 months is not shown since many patients had discontinued by that stage, and not all clinical scores were available at the time of discontinuation. Of the 154 patients who started the study, 110 remained at the 12-month followup.

The overall improvement in DAS28 score at 3 months was significantly greater in nonsmokers $(p=0.008)$. Examination of the individual measures that make up the DAS28 score showed that the improvements in tender joint count (TJC28) and PGA were significantly greater in nonsmokers ( $\mathrm{p}=0.008$ and 0.005 , respectively), while improvements in swollen joint count (SJC28) and ESR were not significantly different. Of the other measures, improvement in the pain VAS was significantly greater in nonsmokers $(\mathrm{p}=$ 0.009).

Association of py history with response to TNF antagonists. We found a significant inverse relationship between improvement in the DAS28 score at 3 months and number of py $(\mathrm{R}=-0.28, \mathrm{p}=0.002$; Figure $1 \mathrm{~A})$. This was reflected by an increasing trend of no response at 3 months with increasing py history ( $\mathrm{p}$ for trend $=0.008$; Table 3 ). Patients with the greatest number of py $(>30)$ were 5.8 times more likely to show no response at 3 months than patients who had never smoked $(\mathrm{p}=0.015)$. A similar trend of no response was seen at 12 months ( $\mathrm{p}$ for trend $=0.003$ ), although by this time the association of no response with $>$ 30 py was markedly greater than that with lower pack-year categories (Table 3 ).

Multivariate logistic regression analyses showed that the association of py history with response at 3 and 12 months was independent of age, sex, disease duration, baseline DAS28 score, HAQ score, nodular disease, IgM-RF status, and number of previous DMARD (Model 1, Table 4). The association of py history with response was also independent of current smoking status at baseline. Replacement of IgM-RF status by IgM-RF levels in these analyses made little difference to the association of py history with response, and no association was seen between IgM-RF levels and response (data not shown). When all baseline variables were included in a forward stepwise model, the py history and number of previous DMARD were the only variables to significantly predict a lack of response at 3 and 12 months (Model 2, Table 4). Interestingly, in models that omitted py categories, current smoking was not associated with response failure at 3 months, but was significantly associated with response failure by 12 months after adjusting for other baseline variables (OR 2.7, 95\% CI 1.2-5.9, $\mathrm{p}=0.01$ ).

Examination of individual measures of the DAS28 score indicated that the inverse relationship between py history and DAS28 improvement at 3 months could be explained mainly by an inverse relationship between the number of py and improvements in TJC28 and PGA $(\mathrm{R}=-0.25, \mathrm{p}=0.006$ and $\mathrm{R}=-0.21, \mathrm{p}=0.02$, respectively). There was no relationship between number of py and improvements in SJC28

Table 2. Comparison of clinical variables at baseline and 3 months in smokers and nonsmokers treated with TNF antagonists.

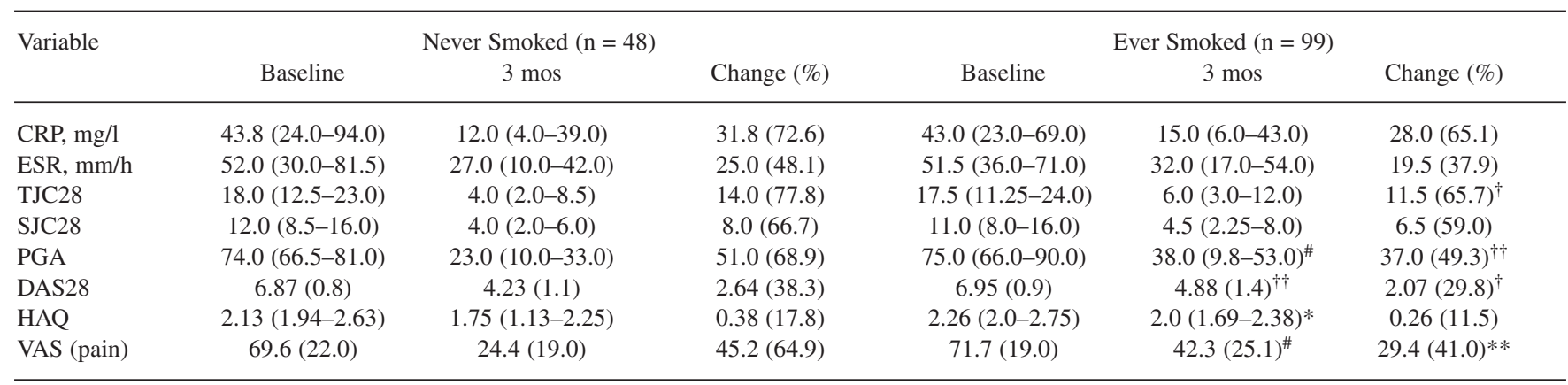

All clinical variables in smokers and nonsmokers were significantly lower at 3 mos compared with baseline $(\mathrm{p}<0.0001)$. Patients who had ever smoked demonstrated significantly higher levels and lower percentage changes of many variables at 3 months; $* \mathrm{p}=0.01, * * \mathrm{p}=0.009,{ }^{\dagger} \mathrm{p}=0.008,{ }^{\dagger \dagger} \mathrm{p}=0.005,{ }^{\#}$ $\mathrm{p} \leq 0.0004$ (compared with never smoked). CRP: C-reactive protein; ESR: erythrocyte sedimentation rate; TJC: tender joints; SJC; swollen joints; PGA: patient global assessment; DAS: Disease Activity Score; HAQ: Health Assessment Questionnaire; VAS: visual analog scale. Mean (standard deviation) shown for DAS28 and VAS (pain) scores. All other scores show median (interquartile range).

Personal non-commercial use only. The Journal of Rheumatology Copyright @ 2009 . All rights reserved. 
A

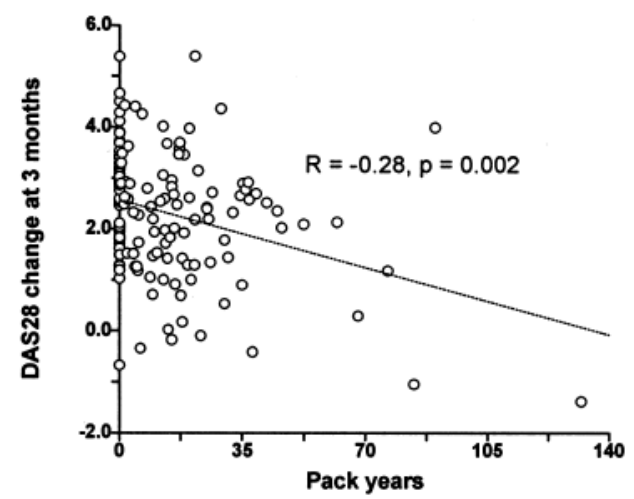

B

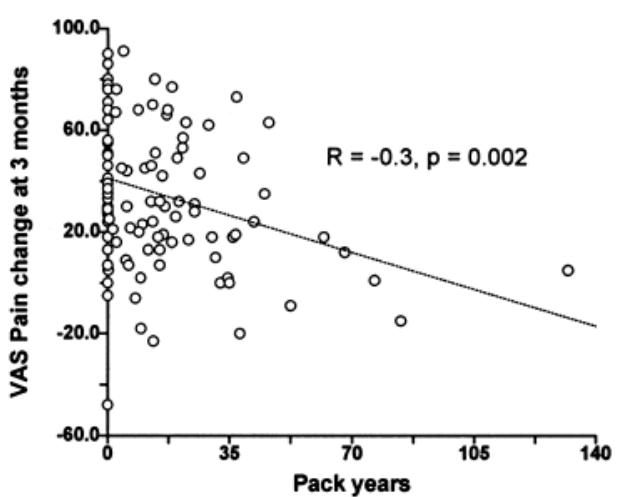

Figure 1. Inverse relationship between (A) Disease Activity Score 28 or (B) visual analog scale pain score change at 3 months and number of pack-years.

Table 3. Relationship between pack-year history and response to TNF antagonists.

\begin{tabular}{lccc}
\hline Pack-years & $\begin{array}{c}\text { Response, } \\
\mathrm{n}(\%)\end{array}$ & $\begin{array}{c}\text { No Response, } \\
\mathrm{n}(\%)\end{array}$ & $\begin{array}{c}\text { Odds Ratio } \\
(95 \% \mathrm{CI})\end{array}$ \\
\hline 3 months & & & \\
0 & $48(94.1)$ & $3(5.9)$ & $1.0(\mathrm{ref})$ \\
$1-15$ & $42(84.0)$ & $8(16.0)$ & $2.8(0.7-10.3)$ \\
$16-30$ & $25(78.1)$ & $7(21.9)$ & $4.1(1.04-15.8)$ \\
$>30$ & $15(68.2)$ & $6(31.8)$ & $5.8(1.4-24.0)^{*}$ \\
12 months & & & $1.0(\mathrm{ref})$ \\
0 & $33(66.0)$ & $18(34.0)$ & $1.7(0.8-3.7)$ \\
$1-15$ & $26(50.0)$ & $24(50.0)$ & $1.4(0.6-3.5)$ \\
$16-30$ & $18(51.7)$ & $14(48.3)$ & $7.0(2.2-22.9)^{* *}$ \\
$>30$ & $4(19.0)$ & $17(81.0)$ &
\end{tabular}

$* \mathrm{p}($ chi-square test for trend $)=0.008 . * * \mathrm{p}($ chi-square test for trend $)=0.003$.

and ESR. Of the other disease measures, improvement in the HAQ and pain VAS also showed significant inverse relationships with number of py $(\mathrm{R}=-0.21, \mathrm{p}=0.01$ and $\mathrm{R}=$ $-0.3, p=0.002$, respectively; Figure $1 \mathrm{~B})$. There was a strong correlation between change in the DAS28 score and change in the pain VAS at 3 months $(\mathrm{R}=0.45, \mathrm{p}<0.0001)$.

Smoking and response to individual TNF antagonists. We investigated whether poor response in smokers was associated with the use of a particular TNF antagonist. For these analyses we examined the response to infliximab and etanercept separately. The response of patients taking adalimumab was not reported because of the small numbers treated with this drug. A significant trend of nonresponse with increasing py history was seen in patients treated with infliximab by 3 months and this approached significance at 12 months followup (Table 5). A significant trend was not seen in the etanercept-treated patients, although by 12 months followup, patients who had smoked $>30$ py were more likely to have shown response failure than all those in the other groups (OR 5.1, 95\% CI 1.1-23.8).

\section{DISCUSSION}

Although TNF antagonists provide effective treatment in RA patients with severe disease there is a significant proportion $(\sim 30 \%)$ that show little or no response $\mathrm{e}^{24-31}$. Factors that have been associated with poor response include certain genetic polymorphisms, previous DMARD failure, increased disease duration, increased disability, and female sex $^{32-37}$. In our study, we found that RA patients with a history of smoking were more likely to show a poor DAS28 response to anti-TNF treatment by 3 months and 12 months followup. Multivariate analyses suggested that the association of smoking with response failure was independent of baseline disease activity, severity, and functional disability measures. An important finding of our study was that the lack of response was associated with the intensity of previous smoking, irrespective of whether the patient was smoking at the time of starting therapy.

A study by Hyrich, et $a l^{19}$ suggested that there was a lower response rate by 6 months among current smokers receiving infliximab, but no association between smoking and outcome in patients taking etanercept. Investigation of infliximab and etanercept separately in our study suggested that the response to the former over the first 3 months was more likely to be influenced by py history, although by 12 months a poor response to both drugs was seen in those patients who had smoked more than 30 py. Approximately $80 \%$ of smokers in this category had demonstrated response failure by this time irrespective of the drug used. It is also worth noting that this category contained the highest frequency of patients who were still smoking at baseline (47.6\%), and may partly explain the association between current smoking and response failure by 12 months when py categories were omitted from the regression model. Some caution is needed in the interpretation of these results because of the relatively small numbers and wide confidence intervals. Further independent studies with larger

Personal non-commercial use only. The Journal of Rheumatology Copyright (c) 2009. All rights reserved. 
Table 4. Multivariate logistic regression analyses of baseline predictors of response failure to TNF antagonists at 3 months and 12 months. Pack-years were split into 4 categories $(0,1-15,16-30,>30)$.

\begin{tabular}{|c|c|c|c|c|}
\hline \multirow[t]{2}{*}{ Variable } & \multicolumn{2}{|c|}{ Model 1} & \multicolumn{2}{|c|}{$\begin{array}{c}\text { Model } 2 \\
\text { (forward selection) }\end{array}$} \\
\hline & OR & $95 \% \mathrm{CI}$ & OR & $95 \% \mathrm{CI}$ \\
\hline \multicolumn{5}{|l|}{3 months } \\
\hline Male & 0.63 & $0.19-2.12$ & & \\
\hline Age, yrs & 0.99 & $0.93-1.05$ & & \\
\hline Disease duration, yrs & 0.97 & $0.90-1.04$ & & \\
\hline Nodules $(+/-)$ & 1.58 & $0.50-5.02$ & & \\
\hline Rheumatoid factor $(+/-)$ & 0.83 & $0.24-2.87$ & & \\
\hline DAS28 (per unit) & 0.89 & $0.51-1.54$ & & \\
\hline HAQ (per unit) & 0.39 & $0.13-1.21$ & & \\
\hline No. previous DMARD (per DMARD) & 1.57 & $1.12-2.18$ & 1.52 & $1.10-2.08$ \\
\hline Pack-year category (per category) & 1.95 & $1.11-3.46$ & 1.98 & $1.34-3.13$ \\
\hline Current smoker $(+/-)$ & 1.01 & $0.32-3.24$ & & \\
\hline \multicolumn{5}{|l|}{12 months } \\
\hline Male & 1.25 & $0.54-2.86$ & & \\
\hline Age, yrs & 1.01 & $0.98-1.04$ & & \\
\hline Disease duration, yrs & 1.01 & $0.90-1.06$ & & \\
\hline Nodules $(+/-)$ & 0.62 & $0.27-1.39$ & & \\
\hline Rheumatoid factor $(+/-)$ & 0.97 & $0.41-2.26$ & & \\
\hline DAS28 (per unit) & 0.97 & $0.64-1.44$ & & \\
\hline HAQ (per unit) & 0.75 & $0.33-1.69$ & & \\
\hline No. previous DMARD (per DMARD) & 1.27 & $1.01-1.61$ & 1.23 & $1.00-1.53$ \\
\hline Pack-year category (per category) & 1.57 & $1.05-2.37$ & 1.65 & $1.18-2.30$ \\
\hline Current smoker $(+/-)$ & 1.81 & $0.72-4.51$ & & \\
\hline
\end{tabular}

DMARD: disease modifying antirheumatic drugs; DAS28: Disease Activity Score 28-joint count; HAQ: Health Assessment Questionnaire.

Table 5. Relationship between pack-year history and response to individual TNF antagonists.

\begin{tabular}{lcccccc}
\hline Pack-years & $\begin{array}{c}\text { Response, } \\
\mathrm{n}(\%)\end{array}$ & $\begin{array}{c}\text { Infliximab } \\
\text { no Response, } \\
\mathrm{n}(\%)\end{array}$ & $\begin{array}{c}\text { OR } \\
(95 \% \mathrm{CI})\end{array}$ & $\begin{array}{c}\text { Response, } \\
\mathrm{n}(\%)\end{array}$ & $\begin{array}{c}\text { Etanercept } \\
\text { No Response, } \\
\mathrm{n}(\%)\end{array}$ & $\begin{array}{c}\text { OR } \\
(95 \% \mathrm{CI})\end{array}$ \\
\hline $\begin{array}{l}3 \text { months } \\
0\end{array}$ & $32(100)$ & $0(0)$ & $1.0(\mathrm{ref})$ & $11(78.6)$ & $3(21.4)$ & $1.0(\mathrm{ref})$ \\
$1-15$ & $18(85.7)$ & $3(14.3)$ & $12.3(0.7-53)$ & $19(86.4)$ & $3(13.6)$ & $0.6(0.07-4.5)$ \\
$16-30$ & $15(75.0)$ & $5(25.0)$ & $23.1(1.6-109)$ & $9(90.0)$ & $1(10.0)$ & $0.5(0.01-6.02)$ \\
$>30$ & $8(80.0)$ & $2(31.8)$ & $19.1(0.8-75)^{* *}$ & $6(66.7)$ & $3(33.3)$ & $1.8(0.2-17.7)$ \\
12 month & & & & & & \\
0 & $19(58.1)$ & $13(41.9)$ & $1.0(\mathrm{ref})$ & $9(72.7)$ & $5(27.3)$ & $1.0(\mathrm{ref})$ \\
$1-15$ & $11(52.4)$ & $10(47.6)$ & $1.3(0.4-3.9)$ & $12(52.9)$ & $10(47.1)$ & $1.5(0.4-5.5)$ \\
$16-30$ & $9(45.0)$ & $11(55.0)$ & $1.7(0.6-5.3)$ & $8(75.0)$ & $2(25.0)$ & $0.5(0.1-2.9)$ \\
$>30$ & $2(20.0)$ & $8(80.0)$ & $4.9(1.0-23.6)^{*}$ & $2(22.2)$ & $7(77.8)$ & $5.2(0.9-30.6)$ \\
\hline
\end{tabular}

$* \mathrm{p}$ (chi-square test for trend $)=0.08$. * $\mathrm{p}($ chi-square test for trend $)=0.01$.

sample sizes would clarify whether there are indeed differences between infliximab and etanercept in the response of patients who smoke.

A number of possible mechanisms may be considered to explain our findings. One possibility is that the association with poor response in smokers is due to an increased frequency of RF and anti-cyclic citrullinated peptide (CCP) autoantibodies in these patients. The association of smoking with increased production of RF and anti-CCP in RA is well documented $4,7,8,12,14,17,18,38$, and recent studies have suggested that RF and/or anti-CCP are associated with poor response to anti-TNF ${ }^{39-41}$. One of these ${ }^{40}$ reported that the association between RF and lack of response to TNF antagonists was mostly due to high levels of IgA-RF. In our study we did not have anti-CCP measurements or levels of IgA-RF available. However, high levels of IgA-RF are usually associated with high levels of IgM-RF, and we found no association between IgM-RF levels and response. 
Although there was a strong relationship between IgM-RF status and py, our multivariate analyses suggested that py history was associated with response failure independent of IgM-RF levels and IgM-RF positivity.

Another possibility is that smoking is associated with increased production of human anti-chimeric antibodies against infliximab (HACA) in patients treated with this drug. Such antibodies have been associated with lower serum infliximab concentrations, and with a reduced response to treatment ${ }^{42,43}$. However, we are not aware of any investigation of levels of HACA in patients with RA who smoke, and this could be an area of further study.

Other possibilities include an alteration in the pharmacokinetics of TNF antagonists in smokers, for example by interference with absorption, or more rapid clearance of drug. It is also possible that past and current smokers have higher levels of TNF- $\alpha$ and/or other inflammatory mediators that make them more resistant to anti-TNF therapy. There is evidence that various cytokines and matrix metalloproteinases are elevated in smokers ${ }^{44,45}$, and we have recently reported increased production of TNF- $\alpha$ by $\mathrm{T}$ cells from patients with RA who smoke ${ }^{46}$. In that study, we found an increase in the TNF- $\alpha$ /soluble TNF receptor ratio released by $\mathrm{T}$ cells that was associated with py history, and that remained elevated in past smokers. In contrast to these findings, this study showed no significant differences between smokers and nonsmokers in the levels of the inflammatory markers CRP and ESR, either at baseline or after 3 months' treatment. Also, the change in the levels of these markers during treatment showed no clear association with py history. This might argue against the lack of response being due to an elevation of inflammatory mediators in smokers.

It is noteworthy that the inverse relationship between number of py and DAS28 improvement could be accounted for mainly by a negative relationship between py and improvement in more subjective measures of the DAS28 (TJC28 and PGA). There was also an inverse relationship between py and improvement in pain VAS in these patients. These findings suggest that response failure in smokers may be explained to a large extent by a more severe perception of pain, rather than a failure to reduce inflammatory disease activity. This is in accord with previous studies that have reported greater levels of pain in smokers with musculoskeletal disorders ${ }^{47-50}$. It has been suggested that this could arise from an effect on neurological processing of sensory information, or by general damage to musculoskeletal tissues through vasoconstriction, hypoxia, defective fibrinolysis, etc. ${ }^{50}$. Such neurological and damage effects need not be mutually exclusive, and the dose-response relationship seen between the extent of smoking and pain in a number of studies would support a mechanism involving longlasting rather than transient effects. An alternative explanation is that people who choose to take up and continue smoking demonstrate neuropsychological or sociocultural differences that are reflected by differences in personality or illness behavior and may include a lower threshold for reporting pain and disability ${ }^{50}$.

Whether the effect of smoking on pain perception is due to a systemic effect or confounding by sociocultural factors is unclear, but either way it may have implications for the measurement of response in longterm smokers treated with TNF antagonists. Our data suggest that a history of smoking may place a greater weight on subjective measures of the DAS28 response, most likely through greater pain perception, leading to higher DAS28 scores than those seen in nonsmokers with similar levels of inflammatory activity. This raises the question whether the DAS28 response is the most appropriate measure of improvement in those patients who have a history of smoking. It is worth noting that the majority of patients investigated in our study had severe, longstanding disease so that many already had a significant py history by the time of anti-TNF treatment. The severity of disease in this particular cohort is reflected by the high frequency of nodular disease, and by the relatively high failure rate at 12 months. The criteria for prescribing TNF antagonists in the UK includes failure with at least 2 previous DMARD, so the high disease burden in this particular group may thus limit the generalizability of the study. Patients with RA starting anti-TNF therapy in other countries may have significantly less severe disease.

Further studies are needed to investigate whether patients treated at an earlier stage of their disease show a similar relationship between smoking history and poor response. We also acknowledge that the relatively low number of patients in this study may not provide a definitive conclusion on this relationship, and other studies with larger cohorts will be needed to confirm these findings.

\section{ACKNOWLEDGMENT}

We thank Michelle Kirwan (research nurse) and Janet Turner (research assistant) for their help with data collection and entry.

\section{REFERENCES}

1. Heliovaara M, Ahp K, Aromaa A, Knekt P, Reunanen A. Smoking and risk of rheumatoid arthritis. J Rheumatol 1993;20:1830-5.

2. Silman AJ, Newman J, MacGregor AJ. Cigarette smoking increases the risk of rheumatoid arthritis. Results from a nationwide study of disease-discordant twins. Arthritis Rheum 1996;39:732-5.

3. Symmons DPM, Bankhead CR, Harrison BJ, et al. Blood transfusion, smoking, and obesity as risk factors for the development of rheumatoid arthritis: results from a primary care-based incident case-control study in Norfolk, England. Arthritis Rheum 1997;40:1955-61.

4. Saag KG, Cerhan JR, Kolluri S, Hunninghake GW, Schwartz DA. Cigarette smoking and rheumatoid arthritis severity. Ann Rheum Dis 1997;56:463-9.

5. Karlson EW, Lee IM, Cook NR, Manson JE, Buring JE, Hennekens $\mathrm{CH}$. A retrospective cohort study of cigarette smoking and risk of rheumatoid arthritis in female health professionals. Arthritis Rheum 1999;42:910-7.

6. Uhlig T, Hagen KB, Kvein TK. Current tobacco smoking, formal education, and the risk of rheumatoid arthritis. J Rheumatol

Personal non-commercial use only. The Journal of Rheumatology Copyright @ 2009 . All rights reserved. 
1999;26:47-54.

7. Wolfe F. The effect of smoking on clinical, laboratory and radiographic status in rheumatoid arthritis. J Rheumatol 2000;27:630-7.

8. Masdottir B, Jonsson T, Manfredsdottir V, Vikingsson A, Brekkan A, Valdimarsson H. Smoking, rheumatoid factor isotypes and severity of rheumatoid arhritis. Rheumatology 2000;39:1202-5.

9. Hutchinson D, Shepstone L, Moots R, Lear JT, Lynch MP. Heavy cigarette smoking is strongly associated with rheumatoid arthritis (RA), particularly in patients without a family history of RA. Ann Rheum Dis 2001;60:223-7.

10. Harrison BJ, Silman AJ, Wiles NJ, Scott DG, Symmons DP. The association of cigarette smoking with disease outcome in patients with early inflammatory polyarthritis. Arthritis Rheum 2001;44:323-30.

11. Mattey DL, Hutchinson D, Dawes PT, et al. Smoking and disease severity in rheumatoid arthritis. Association with polymorphism at the gluatathione S- transferase (GST) M1 locus. Arthritis Rheum 2002;46:640-6.

12. Mattey DL, Dawes PT, Clarke S, et al. Relationship among the HLA-DRB 1 shared epitope, smoking and rheumatoid factor production in rheumatoid arthritis. Arthritis Rheum 2002;47:403-7.

13. Mattey DL, Dawes PT, Fisher J, et al. Nodular disease in rheumatoid arthritis: Association with cigarette smoking and HLA-DRB1/TNF gene interaction. J Rheumatol 2002;29:2313-8.

14. Padyukov L, Silva C, Stolt P, Alfredsson L, Klareskog L. A gene-environment interaction between smoking and shared epitope genes in HLA-DR provides a high risk of seropositive rheumatoid arthritis. Arthritis Rheum 2004;50:3085-92.

15. Forslind K, Ahlem M, Eberhardt K, Hafstrom I, Svensson B. Prediction of radiological outcome in early rheumatoid arthritis in clinical practice: role of antibodies to citrullinated peptides (anti-CCP). Ann Rheum Dis 2004;63:1090-5.

16. Finckh A, Dehler S, Costenbader KH, Gabay C. Cigarette smoking and radiographic progression in rheumatoid arthritis. Ann Rheum Dis 2007;66:1066-71.

17. Klareskog L, Stolt P, Lundberg K, et al. A new model for an etiology of rheumatoid arthritis: Smoking may trigger HLA-DR (shared epitope)-restricted immune reactions to autoantigens modified by citrullination. Arthritis Rheum 2006;54:38-46.

18. Westhoff G, Rau R, Zink A. Rheumatoid arthritis patients who smoke have a higher need for DMARDs and feel worse, but they do not have more joint damage than non-smokers of the same serological group. Rheumatology 2008;47:849-54.

19. Hyrich KL, Watson KD, Silman AJ, Symmons DPM and The BSR Biologics Register. Predictors of response to anti-TNF- $\alpha$ therapy among patients with rheumatoid arthritis: results from the British Society for Rheumatology Biologics Register. Rheumatology 2006;45:1558-65.

20. Arnett FC, Edworthy SM, Bloch DA, et al. The ARA 1987 revised criteria for classification of rheumatoid arthritis. Arthritis Rheum 1988;31:315-24.

21. Fries J, Spitz P, Young D. Dimensions of health outcomes: the Health Assessment Questionnaire, disability and pain scales. J Rheumatol 1982;9:789-93.

22. Wolfe F. A comparison of IgM rheumatoid factor by nephelometry and latex methods: Clinical and laboratory significance. Arthritis Care Res 1998;11:89-93.

23. Van Gestel AM, Haagsma CJ, van Riel PL. Validation of rheumatoid arthritis improvement criteria that include simplified joint counts. Arthritis Rheum 1998;41:1845-50.

24. Maini RN, Breedveld FC, Kalden JR, et al. Therapeutic efficacy of multiple intravenous infusions of anti-tumor necrosis factor alpha monoclonal antibody combined with low-dose weekly methotrexate in rheumatoid arthritis. Arthritis Rheum 1998;41:1552-63.
25. Maini R, St. Clair EW, Breedveld F, et al. Infliximab (chimeric anti-tumour necrosis factor alpha monoclonal antibody) versus placebo in rheumatoid arthritis patients receiving concomitant methotrexate: a randomised phase II trial. ATTRACT Study Group. Lancet 1999;354:1932-9.

26. Weinblatt ME, Kremer JM, Bankhurst AD, et al. A trial of etanercept, a recombinant tumor necrosis factor receptor:Fc fusion protein in patients with rheumatoid arthritis receiving methotrexate. N Engl J Med 1999;340:253-9.

27. Kavanaugh A, St. Clair EW, McCune WJ, Braakman T, Lipsky P. Chimeric anti-tumour necrosis factor-alpha monoclonal antibody treatment of patients with rheumatoid arthritis receiving methotrexate therapy. Rheumatology 2000;27:841-50.

28. Lipsky PE, van der Heijde DMFM, St. Clair EW, et al. Infliximab and methotrexate in the treatment of rheumatoid arthritis. $\mathrm{N}$ Engl $\mathrm{J}$ Med 2000;342:1594-602.

29. Klareskog L, van der Heijde DMFM, de Jager JP, et al. Therapeutic effect of the combination of etanercept and methotrexate compared with each treatment alone in patients with rheumatoid arthritis: double-blind randomised controlled trial. Lancet 2004;363;675-81.

30. Weinblatt ME, Keystone EC, Furst DE, et al. Adalimumab, a fully human anti-tumor necrosis factor alpha monoclonal antibody, for the treatment of rheumatoid arthritis in patients taking concomitant methotrexate: the ARMADA trial. Arthritis Rheum 2003;48:35-45.

31. van de Putte LB, Rau R, Breedveld FC, et al. Efficacy and safety of the fully human anti-tumour necrosis factor alpha monoclonal antibody adalimumab (D2E7) in DMARD refractory patients with rheumatoid arthritis: a 12 week, phase II study. Ann Rheum Dis 2003;62:1168-77.

32. Mugnier B, Balandraud N, Darque A, Roudier C, Roudier J, Reviron D. Polymorphism at position -308 of the tumor necrosis factor alpha gene influences outcome of infliximab therapy in rheumatoid arthritis. Arthritis Rheum 2003;48:1849-52.

33. Kang CP, Lee KW, Yoo DH, Kang C, Bae SC. The influence of a polymorphism at position -857 of the tumour necrosis factor alpha gene on clinical response to etanercept. Rheumatology 2005;44:547-52.

34. Schotte H, Schluter B, Drynda S, et al. Interleukin 10 promoter microsatellite polymorphisms are associated with response to long term treatment with etanercept in patients with rheumatoid arthritis. Ann Rheum Dis 2005;64:575-81.

35. Tolusso B, Pietrapertosa D, Morelli A, et al. IL-1B and IL-1RN gene polymorphisms in rheumatoid arthritis: relationship with protein plasma levels and response to therapy. Pharmacogenomics 2006;7:683-95.

36. Seitz M, Wirthmuller U, Moller B, Villiger PM. The - 308 tumour necrosis factor-alpha gene polymorphism predicts therapeutic response to TNF alpha-blockers in rheumatoid arthritis and spondyloarthritis patients. Rheumatology 2007;46:93-6.

37. Anderson JJ, Wells G, Verhoeven AC, Felson DT. Factors predicting response to treatment in rheumatoid arthritis: the importance of disease duration. Arthritis Rheum 2000;43:22-9.

38. Linn-Rasker SP, van der Helm-van Mil AHM, Van Gaalen FA, et al. Smoking is a risk factor for anti-CCP antibodies only in RA patients that carry HLA-DRB1 shared epitope alleles. Ann Rheum Dis 2006;65:366-71.

39. Braun-Moscovici Y, Markovits D, Zinder O, et al. Anti-cyclic citrullinated protein antibodies as a predictor of response to anti-tumor necrosis factor-alpha therapy in patients with rheumatoid arthritis. J Rheumatol 2006;33:497-500.

40. Bobbio-Pallavicini F, Caporali R, Alpini C, et al. High IgA rheumatoid factor levels are associated with poor clinical response to tumour necrosis factor alpha inhibitors in rheumatoid arthritis. Ann Rheum Dis 2007;66:302-7.

41. Potter C, Hyrich KL, Tracey A, et al. Association of rheumatoid

Personal non-commercial use only. The Journal of Rheumatology Copyright $\odot$ 2009. All rights reserved. 
factor and anti-cyclic citrullinated peptide positivity, but not carriage of shared epitope or PTPN22 susceptibility variants, with anti-tumour necrosis factor response in rheumatoid arthritis. Ann Rheum Dis 2009;68:69-74.

42. Wolbink GJ, Vis M, Lems W, et al. Development of antiinfliximab antibodies and relationship to clinical response in patients with rheumatoid arthritis. Arthritis Rheum 2006;54:711-5.

43. Bendtzen K, Geborek P, Svenson M, Larsson L, Kapetanovic MC, Saxne T. Individualized monitoring of drug bioavailability and immunogenicity in rheumatoid arthritis patients treated with tumor necrosis factor alpha inhibitor infliximab. Arthritis Rheum 2006;54:3782-9.

44. Cozen W, Diaz-Sanchez D, Gauderman JW, et al. Th1 and Th2 cytokines and IgE levels in identical twins with varying levels of cigarette consumption. J Clin Immunol 2004;24:617-22.

45. Raitio A, Tuomas H, Kokkonen N, et al. Levels of matrix metalloproteinase-2, -9 and -8 in the skin, serum and saliva of smokers and non-smokers. Arch Dermatol Res 2005;297:242-8.
46. Glossop JR, Dawes PT, Mattey DL. Association between cigarette smoking and release of tumour necrosis factor alpha and its soluble receptors by peripheral blood mononuclear cells in patients with rheumatoid arthritis. Rheumatology 2006;45:1223-9.

47. Amin S, Niu J, Guermazi A, et al. Cigarette smoking and the risk for cartilage loss and knee pain in men with knee osteoarthritis. Ann Rheum Dis 2007;66:18-22.

48. Brage S, Bjerkedal T. Musculoskeletal pain and smoking in Norway. J Epidemiol Community Health 1996;26:49-54.

49. Eriksen WB, Brage S, Bruusgard D. Does smoking aggravate musculoskeletal pain? Scand J Rheumatol 1997;26:49-54.

50. Palmer KT, Syddall H, Cooper C, Coggon D. Smoking and musculoskeletal disorders: findings from a British national survey. Ann Rheum Dis 2003;62:33-6. 